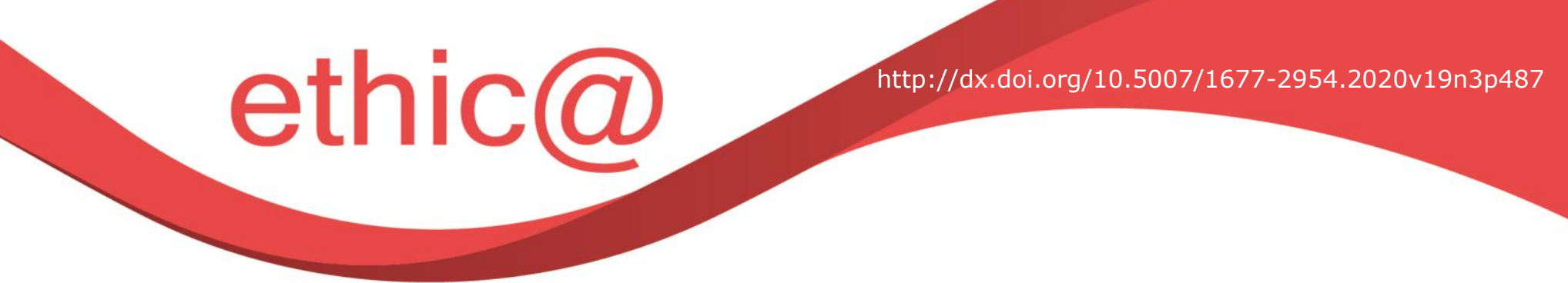

\title{
DA SEMÂNTICA FORMAL À PRAGMÁTICA TRANSCENDENTAL: A IDEIA ORIGINAL DE KARL-OTTO APEL $^{1}$
}

\author{
FROM FORMAL SEMANTICS TO TRANSCENDENTAL \\ PRAGMATICS: KARL-OTTO APEL'S ORIGINAL IDEA
}

\section{JÜRGEN HABERMAS}

\begin{abstract}
RESUMO
Karl-Otto Apel ocupa um lugar de destaque entre os filósofos alemães da primeira geração após a Segunda Guerra Mundial. Sua realização pioneira, que é ofuscada pela disputa acirrada sobre o problema de uma "fundamentação última" da ética, consiste em abrir uma nova dimensão na análise da linguagem e, com isso, completar a "virada linguística". Ele realizou a transição da semântica formal, que se concentra na estrutura dos enunciados, para a pragmática "transcendental" da linguagem, centrada nas propriedades formais do uso e da interpretação das expressões linguísticas. Desta forma, ele também lançou as bases para uma ética do discurso. O ensaio traça as etapas dessa "transformação da filosofia transcendental", que, partindo do Heidegger tardio, conduzem à hermenêutica transcendental inspirada por Peirce. Ao dar continuidade a uma discussão que transcorreu ao longo de toda a vida com meu amigo Karl-Otto, enfrento, no final, alguns problemas que, a meu ver, surgem dessa fundamentação da ética do discurso.
\end{abstract}

Palavras-chave: Filosofia na Alemanha do pós-guerra; Heidegger; Peirce; Pragmática transcendental; Ética do discurso.

\begin{abstract}
Karl-Otto Apel occupies a preeminent place among the German philosophers of the first postwar generation. His groundbreaking achievement, which has been unjustly overshadowed by the tenacious debate over the "ultimate justification" of ethics, consisted in disclosing a new dimension in the philosophy of language and thereby completing the "linguistic turn." He made the transition from formal semantics, which concentrates on the structure of propositions, to "transcendental" pragmatics of language, which focuses on the formal aspects of the use and interpretation of linguistic expressions. In pursuing this path, he also laid the foundations for discourse ethics. The essay traces the stages of this "transformation of transcendental philosophy" leading from the late Heidegger to Apel's conception of "transcendental hermeneutics" inspired by Peirce. Continuing the lifelong discourse with my friend Karl-Otto, I will conclude by addressing some problems raised by his justification of discourse ethics.
\end{abstract}


Keywords: Philosophy in postwar Germany; Heidegger; Peirce; Transcendental pragmatics; Discourse ethics.

A obra de Karl-Otto Apel representa uma das realizações filosóficas revolucionárias do século $X X$. Infelizmente, nas últimas décadas de sua carreira, o próprio Apel deslocou a atenção de seus colegas do tema central da filosofia da linguagem e do caminho em direção à ética do discurso para o tema secundário de sua "fundamentação última". Gostaria de justificar minha avaliação não convencional desses temas retraçando as etapas mais importantes do caminho de pensamento de Apel desde sua habilitação em 1959 até a segunda parte do segundo volume de Transformação da filosofia de 1973; essas etapas refletem a transformação de seu próprio pensamento. As ideias fundamentais de Apel são o resultado dos processos de aprendizagem que ele realizou durante esse período, mesmo que a elaboração de sua ética do discurso tenha ocorrido apenas mais tarde. ${ }^{2}$ Pode ser útil indicar qual era a situação acadêmica em que se encontravam os estudantes de filosofia de nossa geração após a Segunda Guerra Mundial e durante a primeira metade da década de 1950; pois em universidades tradicionais como Bonn, era comum, no início da República Federal, eles encontrarem tradições que continuavam inabaladas desde a década de 1920 e o período nazista.

Duas tradições capazes de satisfazer um interesse sistemático estavam presentes no ensino universitário naquele momento: por um lado, a fenomenologia que os alunos de Husserl continuaram produtivamente, sobretudo com a análise do ser-aí desenvolvida em Ser e tempo, à qual Martin Heidegger, como só se perceberia com atraso, daria em sua chamada filosofia tardia uma direção completamente diferente no que se refere ao diagnóstico do tempo; por outro lado, a antropologia filosófica fundada por Max Scheler e Helmut Plessner também tinha uma certa atualidade, a qual, por sua vez, era representada mais por Arnold Gehlen (através da segunda edição politicamente higienizada de Der Mensch) do que por Plessner, que só retornou da emigração em 1952. Naquela época, Heidegger e Gehlen eram os autores mais desafiadores sistematicamente nas universidades alemãs. Karl Jaspers também esteve presente com sua Filosofia em três volumes e seus últimos escritos; acima de tudo, ele gerou polêmica com seu importante texto sobre $A$ questão da culpa, publicados logo após a guerra e conceitualmente esclarecedor, e, com razão, gozou de ampla visibilidade até sua morte; embora entre os estudantes ele realmente não tenha despertado paixão filosófica. O continente do neokantianismo havia desaparecido; e o novo hegelianismo também presente em Bonn em pessoas como Theodor Litt, tampouco poderia assumir um perfil 
independente, do mesmo modo que a filosofia da vida não pudera em relação à corrente fenomenológica-hermenêutica predominante. O cenário era mais ou menos esse, não apenas em Bonn. Mas aqui, Oskar Becker estabeleceu um vínculo pessoal com Husserl e Heidegger, enquanto Erich Rothacker espalhava em suas preleções os frutos da erudição hermenêutica da Escola Histórica de Ranke e Savigny a Wilhelm Dilthey e Karl Bühler. Em seus seminários de psicologia, ele tratou da literatura especializada sobre antropologia filosófica, enquanto os temas da filosofia da cultura e da linguagem (embora a ciência da linguagem "substantiva" sempre fora tratada pela tradição bem alemã que remonta a Humboldt, representada naquele momento por Lohmann, Trier e Weißgerber) apareceram especialmente no departamento de filosofia. Mas os alunos inteligentes não apenas se prendem ao currículo, mas também descobrem as lacunas óbvias nele. Sartre e Simone de Beauvoir eram mencionados apenas de modo casual. O que faltava completamente era uma discussão informada das duas tendências da filosofia analítica prevalecentes nos países anglosaxões, à qual Apel se dedicaria - e mais ainda, faltava uma discussão da teoria social do marxismo ocidental, que estava viva principalmente na França ou retornava à Alemanha depois da emigração. Não conseguíamos esconder $o$ isolamento do cânone especificamente alemão em relação às teorias do ocidente e do oriente, sejam elas vitais ou, como no caso da Diamat, teorias que se vincularam ao poder político. Tivemos que nos familiarizam com elas por iniciativa própria e de maneira independente.

Apesar de seu choque moral com os reveladores crimes nazistas, Apel era inicialmente bastante apolítico, de modo que só tomou a sério os impulsos filosóficos levados adiante pela Teoria Crítica da sociedade depois de retomarmos, no final dos anos 1950, o contato que havia sido interrompido depois de nosso tempo juntos em Bonn. Como mostra o capítulo introdutório à sua tese de habilitação, escrito post festum, isto é, no início dos anos 1960, ele estava inicialmente interessado em vincular o universo filosófico de pensamento determinado por Heidegger e Gehlen com as discussões anglo-saxônicas (APEL, 1963). Para ele, a tradição da filosofia da linguagem constituía uma ponte entre os dois continentes que Apel viu encarnados em Aristóteles e Kant, por um lado, e no humanismo italiano e Gianbattista Vico, por outro. A partir disso, ele traça linhas tênues entre a semântica lógica da Escola de Viena e Wittgenstein, por um lado, e a filosofia hermenêutica da linguagem de Wilhelm von Humboldt, por outro. Curiosamente, Kant desempenha aqui também o papel de uma dobradiça. Enquanto este último permanece, na conclusão da tese de habilitação apresentada em 1959, em última análise, um elo subordinado na cadeia da "história do ser" ocidental, ele passa a ter a última palavra em relação à 
filosofia tardia de Heidegger após a Transformação da filosofia (1973), ainda que na forma alterada da pragmática linguística. Foi seguindo desse modo que Apel se apropriou inicialmente do pragmatismo de Charles Sanders Peirce. Do meu ponto de vista, sua realização realmente original consistiu em ter aberto a porta para a transição da semântica lógica para a pragmática formal, traduzindo a abordagem da filosofia transcendental do paradigma da filosofia da consciência para o da filosofia da linguagem. Desse modo, indo além da semântica, também tornou o emprego de proposições em atos de fala acessível a uma análise lógica. É claro que Wittgenstein já havia voltado o olhar para essa estrutura profunda de atos de fala, mesmo que no Tractatus o fizesse de uma maneira diferente das Investigações Filosóficas: lá, a estrutura linguística do mundo, entendida em termos transcendentais, deveria apenas se "mostrar" em evidências não linguísticas, enquanto nas Investigações filosóficas, a unidade da razão parecia se dissolver na variedade descritiva dos contextos dos jogos de linguagem. Mesmo o último Wittgenstein não submeteu as operações da razão, que escapavam completamente à pragmática empírica, a nenhuma análise sistematicamente universalizante.

Gostaria de delinear o caminho de Apel para a lógica do entendimento no discurso - Humboldt já distinguia entre a estrutura gramatical da "linguagem", enquanto ergon, e a energeia da "conversação" presente no uso da linguagem - nas seguintes etapas. Inicialmente, caracterizo o ponto de partida no momento de sua tese de habilitação. Desde o início, Apel estava preocupado com a pretensão universalista do logos aristotélico e a apercepção transcendental de Kant; o protesto dessas vozes contra o pensamento histórico da tradição hermenêutica e sua tendência ao relativismo retumbou cada vez mais claramente em um pensamento que foi inicialmente cativado pela visão de Heidegger de uma história abrangente do ser entendida enquanto história da metafísica ocidental (1). Em seguida, vou relembrar brevemente a teoria dos interesses do conhecimento por meio da qual Apel retomou o legado de Gehlen. Essa abordagem antropológica do conhecimento e o impulso da crítica política que foi simultaneamente dirigida a Gehlen poderiam ter libertado a pretensão universalista da razão já claramente perceptível do contextualismo da história do ser; mas, a esse respeito, a crítica de Apel ainda estava presa em uma ambiguidade peculiar (2). É verdade que Apel abre o caminho metodológico para uma abordagem pragmática do pensamento hermenêutico; mas a ruptura em direção à pragmática formal só aconteceu com o auxílio de uma interpretação transcendental da semiótica por Charles Sanders Peirce - a saber, que ele entende o discurso da comunidade de pesquisa ao mesmo tempo como um a priori da 
comunicação linguística em geral eticamente interpretado (3). Com a incorporação da "comunidade ilimitada de interpretação do pesquisador" no mundo da vida da "comunidade ilimitada de interação do mundo da vida", o fundamento da argumentação incontornável muda para a prática cotidiana. Ao mesmo tempo, o "ethos do entendimento", que surge na orientação para o entendimento em operação na ação comunicativa e que deve residir em toda argumentação, recebe um estatuto transcendental (4). No entanto, contra essa via de uma fundamentação última, depõe o fato de que o sentido forte de validade moral não pode ser obtido a partir dos conteúdos idealizadores dos pressupostos universais e necessários do discurso. Apel, ao contrário, teme as consequências relativistas de uma insustentável destranscendentalização da razão. Ele responde a essa preocupação com uma parte $B$ adicional de sua ética, que, no entanto, não poderá ser discutida (5). Na minha opinião, a questão que surge na modernidade secular, a saber: por que devemos ser morais, não pode ser rejeitada como sem sentido nem respondida no âmbito de uma ética deontológica da razão. No final, pretendo esboçar muito brevemente a resposta que poderia Ihe dar uma filosofia que transforma Kant como um todo (6).

(1) O ensaio sobre o conceito filosófico de verdade publicado em 1959 (APEL, 1973a) revela uma estreita afinidade temática com a tese de habilitação; no entanto, é provável que tenha sido escrito antes da conclusão da introdução a esta publicação, que claramente só foi escrita posteriormente por ocasião de sua publicação em 1963. Em todo caso, esse ensaio ainda reflete o entendimento de Heidegger da verdade como "desencobrimento", que deve ter precedência sobre a verdade do enunciado (designada por Rothacker como "correção"): com Vico, cuja Scientia Nuova apresenta a ideia linguística enraizada no humanismo, "falta apenas um passo para a compreensão geral de que a 'correção' no sentido do conceito aristotélico de verdade, se for verificada em enunciados concretos e factuais, pressupõe histórica e sistematicamente a verdade como a 'revelação' (a-letheia) de entes." (APEL, 1973a, 130). Mas, também aqui, Apel já se preocupa com o problema de como, sob esse pressuposto, podese levar em conta a pretensão de universalidade do logos que entra em jogo na verdade do enunciado. Pois essa razão é o que permite a tradução de expressões de uma língua em expressões com o mesmo significado em qualquer outra língua. Cada língua individual, na medida em que transcende "toda a dogmática dos pontos de vista humanos", está "enraizada no logos universalmente válido" (APEL, 1973a, 132). Apel não quer abalar a universalidade da pretensão de verdade, que foi interpretada de maneiras diferentes de Aristóteles a Kant; e, ao mesmo tempo, ele insiste que, em 
última análise, a visão linguística de mundo "dogmática", que "abre concretamente" o mundo objetivo para a respectiva comunidade linguística histórica, tem a tarefa de integrar o a priori histórico da história do ser com a "consciência a priori" que insiste na validade universal. Ele denomina esse acontecimento paradoxal de "integração linguística do mundo", que significa a integração dos objetos encontrados no mundo no respectivo horizonte linguístico. O logos universalmente válido, que só pode se colocar dentro de um horizonte de significado linguisticamente "previamente dado", mas irreversível, deve primeiro definir as condições sob as quais os intérpretes podem determinar o que é ou não o caso. ${ }^{3} \mathrm{~A}$ prioridade sistemática da "verdade" das imagens linguísticas do mundo, que revela o mundo e o torna aberto, em relação à "correção" dos enunciados possíveis nessa língua explica por que os processos de aprendizagem no mundo carecem da força a priori de revisar a própria imagem de mundo estabelecida "como destino" [geschickte] por uma espécie de acontecimento mítico.

Com isso, no entanto, Apel enfrenta certas dificuldades ao realizar suas investigações histórico-filosóficas sobre a ideia de linguagem, pois na história da metafísica não são decisivas as comunidades linguísticas nacionais, mas as tradições internacionais; a história dos efeitos das tradições filosóficas perpassa as imagens de mundo das línguas nacionais e das culturas correspondentes. $\mathrm{Na}$ introdução à tese de habilitação, publicada posteriormente, Apel ainda se prende ao fato de que "a verdade da fala humana não se baseia primordialmente em uma representação logicamente correta de fatos supostamente previamente dados do mundo, mas na interpretação do mundo como uma situação humana significativa que pela primeira vez revela a ordem de fatos" (APEL, 1963, 28). Mas o objetivo historiográfico do trabalho de confrontar a concepção hermenêutica de linguagem com a concepção "logocêntrica" torna o próprio autor ciente da universalidade da razão acentuada de maneira tradicional e o impede de se desviar prematuramente da interpretação antropologicamente universal dos existenciais (isto é, da análise da constituição do homem em Ser e tempo) sobre a "mitologia da história do ser como destino" (APEL, 1973a, 54). Aludindo ao título da minha crítica de Heidegger de $1953^{4}$, ele já enfatiza aqui "que nós devemos compreender necessariamente pensando com Heidegger contra Heidegger - tanto a chamada 'virada' da análise do ser para a história do ser quanto em especial (...) a filosofia da linguagem de Heidegger a partir da abordagem fundamental de uma 'hermenêutica transcendental'"' (APEL, 1973a, 55). A ideia metodológica básica dessa hermenêutica é de natureza transcendental na medida em que, ao explicar o círculo hermenêutico, expõe a peculiar 
"pré-estrutura" da dependência da compreensão do texto em relação àquilo que desde sempre é compreendido no contexto histórico contingente em que o intérprete e seu autor se encontram. Esta "estrutura preliminar" de compreensão reflete um traço fundamental da existência humana - a "compreensão" como um modo de ser-no-mundo, que é constitutivo da possibilidade de lidar empiricamente com as contingências no mundo.

A autorreflexão da compreensão linguística e do entendimento desde que entendamos metodologicamente este como o processo de uma conversação investigativa entre intérprete e autor - levou, do ponto de vista de Apel, a um aprofundamento transcendental das ideias da hermenêutica. A própria razão parece assumir a forma de um modo existencial da existência humana que tem um caráter constitutivo na compreensão tanto nas experiências possíveis como no entendimento fundamentada. Mas, na introdução à tese de habilitação, Apel ainda não consegue chegar a essa interpretação, que é alcançada metodologicamente e voltada para o núcleo racional de compreensão. É apenas a leitura da segunda parte de Verdade e método (1960) de Gadamer que o inspirará a dar esse passo. É verdade que a teoria geral da hermenêutica não surge ela própria como resultado de esforços hermenêuticos, mas surge com a pretensão teórica de uma reflexão geral sobre tal procedimento; Apel, porém, inicialmente levanta a seguinte objeção ao nexo interno entre compreensão e entendimento racional:

A filosofia não pode e não deve ser hermenêutica em outros aspectos: não na medida em que reflete formalmente sobre as conquistas da hermenêutica nas humanidades, mas na medida em que tem que se colocar na conversa dos filósofos que existiram desde os gregos no Ocidente e colocar essa conversa ocidental da filosofia no encontro atual das grandes culturas do mundo; para colocá-lo de forma mais geral: na medida em que reconduz as pessoas do presente à situação de seu ser-no-mundo mediado pela linguagem? (APEL, 1973a, 48).

Assim, Apel apreende historicamente a pretensão de universalidade a partir da reflexão metodológica sobre a "pré-estrutura de compreensão", por meio da qual o logos parece transcender a vinculação destinal [schicksalhafte] a uma pré-compreensão particular, que abre hermeneuticamente a cada vez os entes como um todo, na medida em que reintegra o "a priori da consciência" kantiano ao contexto histórico incontornável da "metafísica ocidental de Anaximandro a Nietzsche" (APEL, 1973a, 57). Como que para excluir qualquer dúvida sobre a força historicamente aprisionadora dessa compreensão do mundo destacada, 
mas particular, diferente daquela de outras culturas mundiais, Apel acrescenta neste ponto: "Heidegger realiza desse modo... o círculo da situação linguístico-hermenêutica da filosofia". Ao mesmo tempo, ele tenta construir uma ponte ousada da "história do ser" ocidental para a "história da linguagem" apelando para o linguista indo-germanista Johannes Lohmann. ${ }^{5}$

(2) Durante o período decisivo de formação na década de 1960, ou seja, entre a tese de habilitação e o ensaio "De Kant a Peirce", publicado em 1970, Apel rompeu com essa dependência em relação ao Heidegger tardio e lançou as bases teóricas para a elaboração da própria abordagem teórica. Nesse contexto, é relevante um artigo sobre Arnold Gehlen publicado em 1962, que trata principalmente da teoria das instituições desenvolvida em Urmensch und Spätkultur (o substituto esclarecido cultural e antropologicamente para o capítulo final de cunho fascista sobre "sistemas de liderança", que foi omitido na segunda edição de sua obra principal Der Mensch). Com uma reflexão epistemológica, Apel se dirige à teoria antropológica da ação de Gehlen, a fim de excluir o significado idealista da função de abertura do mundo da linguagem: "para descobrir fatos reais 'como algo' no mundo, são necessários os pontos de vista realmente assumidos pelas pessoas na 'terra'" (APEL, 1973, I, 133). Esta conexão "naturalista" em um sentido fraco da hermenêutica transcendental com o "a priori corporal" da estrutura de ação (e, portanto, com a constituição física do homem no nascimento, com o andar ereto, com a mão, com as ferramentas de linguagem, etc.) contraria a necessidade de Apel de, desde o início, atribuir o sentido transcendental da interpretação linguística do mundo a uma espécie que reproduz sua vida social no mundo por meio da prática do trabalho de suas próprias mãos. De qualquer modo, mesmo em sua tese de habilitação, Apel pressentiu os problemas subsequentes da destranscendentalização inconfessada de um sujeito "transcendental" que existe no mundo porque é entendido como uma comunidade linguística e, no entanto, não mais privado do mundo. Mas três anos depois, o novo debate com Gehlen diz respeito à estabilização institucional do modo de vida do ser humano "aberto ao mundo", livre dos instintos animais, por meio de instituições que controlam a violência. Contra essa tese, Apel defende a tese de que no nível evolutivo de socialização comunicativa de sujeitos capazes de agir, a própria linguagem oferece o equivalente funcional para os programas comportamentais instintivos relacionados a ambientes específicos da espécie, que estão ausentes nos humanos: em vez do vínculo ambiental estabelecido instintivamente, o vínculo criado dogmaticamente por imagens de mundo linguísticas deve ter entrado nas vias correspondentemente pré-interpretadas de um ambiente 
cultural. O contraste entre esta representação liberal de vínculos ambientais baseados apenas no "conteúdo linguístico" e a rígida "determinação institucional" de subjetividade humana errante feita por Gehlen apareceu mais claramente no curso da modernização social: aqui, esta é a tese de Apel, "a subjetividade do espírito moderno, liberta pelas instituições, recai na metainstituição da linguagem".

Essa afirmação, tomada em si mesma, não é surpreendente, ela é inclusive compatível com a história do ser de Heidegger. Mas na frase imediatamente seguinte é perceptível que Apel não enfatiza o poder dogmaticamente prejudicial da abertura do mundo pré-interpretante na meta-instituição da linguagem, ou seja, a característica que a qualifica para compensar a perda de estabilização comportamental ocorrida no curso da modernização social; em vez disso, ele retoma o traço antiautoritário do discurso racional, isso é, o entendimento em oposição ao entendimento submisso: "A essência da democracia parlamentar consiste, em última instância, no fato de que as instituições sociais que não são mais autoevidentes emergem da instituição da conversação razoável" (APEL, 1973b, 217). ${ }^{6}$ Com isso, o papel transcendental do entendimento intersubjetivo passa do poder de direção do entendimento prévio sobre o mundo como um todo, que é compartilhado pelos membros de uma comunidade linguística, para o poder antiautoritário do discurso racional com o qual os próprios participantes, indo além do dissenso e da contradição, chegam a um acordo fundamentado. Em termos humboldtianos: embora Apel tenha atribuído anteriormente uma função transcendental à "imagem de mundo linguística" no curso de uma análise aprofundada da pré-compreensão hermenêutica, isso agora deve se estender implicitamente à força unificadora que opera no logos da "conversação razoável". Desse modo, ele continua: "A filosofia é agora sem dúvida - desde os dias em que discutiu pela primeira vez os fundamentos da constituição do Estado e da moralidade humana no diálogo com seres humanos individuais - a verdadeira 'idee directrice' [idea diretriz] de meta-instituição da linguagem livre do mito e das instituições correspondentes, a qual, como 'logos', deveria por sua vez estabelecer todas as outras instituições humanas." E para evitar qualquer mal-entendido elitista nessa frase, ele diz em seguida: "Vista desta forma, a democracia parlamentar é uma incorporação institucional do espírito da filosofia, ou seja, uma filosofia moderadamente cética e generosamente otimista, que não questiona a própria verdade..., mas antes confia sua descoberta parcial, sob as condições de finitude, a cada ser humano como um parceiro de conversa" (APEL, 1973b, 217 ss.).

Nessa grandiosa declaração de 1962, expressa-se a impecável consciência [Gesinnung] kantiana de um grande filósofo do século XX; ela 
se refere também ao enraizamento pragmático do logos e à reflexão sobre a validade de um entendimento entre os membros de uma comunidade de comunicação especializada na troca discursiva de experiências e razões. Mas serão necessários mais seis anos para que Apel generalize o exemplo do discurso parlamentar e tire as conclusões decisivas para a introdução da pragmática formal a partir do estudo de Peirce. Porque ainda não estava claro como a dimensão transcendental da possibilidade da compreensão linguística em geral, isto é, a razão justificadora em operação na "conversação", trabalhará conjuntamente com a pré-estrutura transcendental da linguagem que interpreta o mundo como um todo na compreensão e aplicação de proferimentos linguísticos, isto é, com as instruções de interpretação inscritas na imagem linguística do mundo. O esclarecimento dessa questão é dificultado pela elaboração de uma filosofia da ciência em termos antropológicos, à qual Apel (1973c) se dedicará em meados da década. Porque no campo conceitual da interação complementar de compreensão hermenêutica e reflexão sobre a validade, de a priori da linguagem e a priori da consciência, o interesse do conhecimento técnico das ciências naturais, cujo empirismo supostamente depende do a priori corporal da intervenção experimental direcionada em eventos naturais, não faz jus, como seria de esperar, à razão universal; paradoxalmente, o conhecimento empírico é deslocado para o lado do a priori da linguagem que abre o mundo. A intuição que orienta Apel é a ideia de que com o interesse em tornar a natureza disponível à intervenção instrumental - de forma similar às perspectivas de uma visão linguística de mundo - um ponto de vista relevante em termos práticos para um possível engajamento no mundo foi decidido de antemão e está estabelecido para sempre:

O sentido do questionamento da física, a meu ver, não se torna compreensível apenas recorrendo às funções da (categorias) da consciência (sintética) 'unificadora'. Isso também pressupõe uma 'unificação' linguística dos pesquisadores na compreensão do sentido da natureza e, inclusive, na possibilidade de perceber o questionamento por meio de uma intervenção instrumental na natureza (...) que é pressuposta a priori em todo experimento (...) (Nisso) torna-se preciso o envolvimento do mundo corporal dos órgãos sensoriais, que já é pressuposto na experiência précientífica: o 'medir-se' do homem 'com' a natureza torna-se a 'medição' da ciência experimental (APEL, 1973c, 96).

A interpretação pragmática do experimento como tal não é contraintuitiva, mas a desconsideração da diferença decisiva entre o a priori 
corporal que se realiza na intervenção experimental e o a priori da visão linguística de mundo; enquanto esta lança um olhar particularista sobre o mundo, o a priori corporal compartilha com o a priori da consciência o fato de levantar pretensões da verdade gerais e universalistas. ${ }^{7} \mathrm{Em}$ contrapartida, Apel insiste na suposta analogia entre os dois: "A linguagem, assim como a intervenção técnico-material, aponta para um a priori peculiar, subjetivo, que não era considerado na epistemologia tradicional a partir de Descartes (...) conhecimento pela reflexão e conhecimento pelo engajamento constituem dois polos opostos" (APEL, 1973c, 99). Apenas o estudo mais detido de Peirce chamará a atenção de Apel para o papel constitutivo da comunidade de comunicação dos cientistas naturais que interpretam suas hipóteses teóricas e as verificações experimentais dessas hipóteses. Isso abrirá seus olhos para a falibilidade da pré-compreensão canalizada linguisticamente e o poder de revisão dos processos de aprendizagem intramundanos que se estendem à imagem da natureza como um todo. Ao mesmo tempo, altera-se a importância relativa entre uma hermenêutica, que se refere ao a priori historicamente relativo de uma pré-compreensão fundamentalmente revisável do conteúdo linguístico, de um lado, e o discurso em princípio ilimitado dos pesquisadores de outro. Isso se baseia nas condições quase transcendentais, enraizadas na constituição fundamental da socialização comunicativa dos sujeitos atuantes, que permitem a crítica das pretensões de verdade. Com essa ideia, inspirada em Peirce, Apel vai finalmente superar sua dependência em relação ao último Heidegger.

3) Se Apel havia até o momento circunscrito, em vez de ter analisado, a "reflexão sobre a validade", como contraponto à hermenêutica, por meio de associações kantianas com um "a priori da consciência", ele agora conduz o logos, antes pensado em termos de filosofia do sujeito, ao paradigma da linguagem com a ajuda da transformação semiótica da teoria do conhecimento kantiana realizada por Peirce. Peirce havia se colocado "renovar a questão de Kant sobre as condições da possibilidade de juízos empíricos objetivos como a questão da possibilidade de uma compreensão intersubjetiva do sentido e da verdade das proposições e sistemas de proposições" (APEL, 1973d, 163). A comunidade de pesquisadores agora ocupa o lugar do sujeito transcendental. Estes realizam experimentos para testar hipóteses; mas a atenção do teórico do conhecimento se dirige à disputa discursiva sobre a interpretação correta de experiências que necessitam de explicação; os pesquisadores discutem sobre a interpretação de seus dados coletados à luz de hipóteses, bem como à luz de teorias concorrentes sobre as próprias hipóteses. A dinâmica do processo cognitivo reside no discurso sobre interpretações controversas. Peirce entende a 
comunidade de investigação como uma comunidade de comunicação cujos participantes se orientam pela verdade compreendida universalmente de enunciados em princípio falíveis. Consciente dessa falibilidade, "verdade" não pode significar nada mais do que a expectativa bem fundada de que afirmações consideradas até o momento verdadeiras serão incluídas em um final consensus [consenso final] a ser alcançado ao final dos dias, que se estenderá a tudo o que é o caso. Essa ideia reguladora de um "acordo final" se reflete nas idealizações correspondentes: a comunidade de investigação deve ser considerada ilimitada e o próprio processo de investigação como uma cadeia de interpretações que se estende ao infinito. "Realidade" é então a totalidade dos fatos sobre os quais essa comunidade de interpretação um dia seria capaz de concordar enquanto consenso final. A "coisa em si" é liquidada por esse conceito de realidade, mas se mantém a relação transcendental da realidade cognoscível com o conhecimento possível de tal comunidade de investigação ilimitada. Para Peirce, a reflexão filosófica não pode ir aquém do processo de argumentação do pesquisador assim como, para Kant, não pode ir aquém das operações sintéticas do sujeito transcendental. Uma filosofia transcendental assim transformada "trata principalmente de refletir sobre o sentido - e na medida em que também sobre as implicações do sentido - da argumentação em geral. Isto é (...) para aqueles que argumentam - não importa em qual posição obviamente o fundamento último intransponível" (APEL, 1973e, 222). Para Apel, essa concepção teve a vantagem de juntar, em duas etapas, aquelas tradições de análise da linguagem contemporânea, que dão continuidade à compreensão universalista da razão de Aristóteles e Kant, com a tradição hermenêutica.

O primeiro ponto de contato é o aspecto pragmático, sob o qual o uso da linguagem se torna um tema relevante para a compreensão hermenêutica das ciências humanas e sociais, bem como para o processo de pesquisa nas ciências naturais. Reconhecemos a mesma situação comunicativa inicial se estendemos a situação hermenêutica de pergunta e resposta, que existe nas humanidades entre o intérprete e o autor de um texto a ser interpretado, a uma disputa discursiva entre pesquisadores experimentais sobre um interpretandum correspondente. Essa comunalidade é especificada pelas ciências naturais, entretanto, pelo acesso metodológico ao âmbito objetual, ou seja, testando hipóteses e construindo teorias com base em medições físicas e experimentos. Mas enquanto a compreensão hermenêutica visa a explicação do sentido do proferimento linguístico, os pesquisadores experimentais buscam a explicação causal verdadeira de um fenômeno empírico e, portanto, também sua descrição correta. Essa diferença entre a explicação do 
significado e a busca da verdade conduz as correspondentes teorias hermenêutica e analítica da linguagem a direções diferentes. A explicação do significado de um texto à luz de uma pré-compreensão simultaneamente explícita direciona o olhar hermenêutico à semântica da linguagem em uso, enquanto a discussão sobre a explicação teórica dos fenômenos empíricos concentra a atenção na construção e na estrutura lógica dos enunciados individuais e nos aspectos pragmáticos da justificação discursiva de sua verdade. De qualquer modo, Peirce define, desde o início, a análise da linguagem como semiótica, isto é, como uma teoria do uso de signos, em que a relação triádica do signo com o objeto designado e com o intérprete constitui o ponto de partida. Essa relação já existe para "índices" e "ícones", mas apenas "símbolos" ou sinais proposicionais têm um sentido autônomo ou completo. Uma proposição pronunciada de forma assertiva representa um fato para um intérprete, na medida em que diz algo sobre um referente "indicado" por meio da atribuição de um predicado "icônico".

$O$ outro ponto de contato entre a hermenêutica e o pragmatismo de Peirce é a natureza do nexo entre verdade e significado, que ambos examinam em direções complementares. A hermenêutica se depara com esse nexo interno na medida em que eleva a possibilidade de tomar um proferimento por verdadeiro de certo modo a padrão de sua interpretação. Um intérprete só pode ter entendido seu texto se ele puder fornecer em princípio as razões que poderiam motivar racionalmente o autor a tomar seus proferimentos como verdadeiros. Na medida em que, como ocorre em Verdade e Método de H. G. Gadamer (1960), se trata da apropriação hermenêutica de textos clássicos, que - como no caso da prática da interpretação teológica ou jurídica - reivindicam validade canônica, colocase o desafio hermenêutico para os intérpretes posteriores principalmente em "transpor" o "intervalo de tempo" em relação ao autor clássico. $\mathrm{Na}$ medida em que o intérprete avança para a compreensão de fundo do autor, a fim de compreender quais razões ele pode ter tido a favor de seus enunciados, ele se torna dialeticamente cada vez mais consciente de seu próprio entendimento anterior - reciprocamente, um se torna explícito à luz do outro. Do ponto de vista das gerações posteriores, a apropriação histórica de um texto com autoridade canônica pode, dessa forma, questionar e relativizar a correção de interpretações anteriores, mas sem prejudicar a pretensão de verdade do texto "mais bem compreendido". É exatamente isso que Gadamer pretende com sua hermenêutica; isso se dirige expressamente contra a crítica de Nietzsche à neutralização debilitante das tradições impositivas por meio da historicização. A hermenêutica de Gadamer quer explicar por que o poder de persuasão das tradições que permaneceram vivas não precisa ser prejudicado mesmo 
quando são objeto hermenêutico de análise das ciências humanas e sociais. É claro que esse estreitamento da hermenêutica como continuação culturalmente refletida das tradições não significa qualquer restrição arbitrária da hermenêutica, desde que se assuma que toda interpretação se move nos caminhos pré-traçados e incorrigíveis de uma visão linguística de mundo ou de uma "história do ser" correspondente. Se essa suposição de um nexo prévio e linguisticamente estabelecida entre verdade e significado for abandonada, a teoria do significado só pode estabelecer um nexo hipotético entre os dois elementos. Nesse sentido, de acordo com a tese da semântica de verdade, entendemos uma proposição quando conhecemos as condições sob as quais ela é verdadeira: compreender uma proposição requer o conhecimento de suas condições de verdade. $O$ mesmo nexo hipotético entre verdade e significado é postulado pelo princípio da pragmática formal (que é claro generalizado de "verdade" para diferentes pretensões de validade a serem esclarecidas discursivamente) segundo o qual entendemos um ato de fala quando conhecermos as razões que o tornam sua pretensão de validade racionalmente aceitável (HABERMAS, 1999).

Essa observação antecipa o desenvolvimento que Apel tornou possível com sua recepção a Peirce. Apel mostra que Peirce, assim como a hermenêutica filosófica, investiga o nexo interno entre verdade e significado de uma forma metodológica. Peirce, é claro, não está preocupado com a análise hermenêutica da compreensão do sentido, mas em uma via complementar com a fixação da verdade de uma crença - the fixation of belief. Peirce desenvolve sua lógica pragmática da investigação analisando os procedimentos de inferência que se interligam de forma instrutiva no desenvolvimento e teste empírico de hipóteses na forma de leis. O ponto de partida é a situação problemática em que sujeitos socializados se enredam quando suas suposições implícitas de orientação de ação são frustradas pela realidade. Isso porque a pesquisa está relacionada de forma muito semelhante à problematização de suposições bem-estabelecidas tomadas por verdadeiras. Os pesquisadores também partem do problema de um fenômeno que necessita de explicação, o qual desafia sua capacidade de criação de hipóteses a fim de encontrar ou "abduzir" uma hipótese possivelmente mais adequada; essa hipótese encontrada especulativamente é então testada indutivamente com base nos casos correspondentes produzidos experimentalmente; e se for confirmado, o fenômeno que necessita de explicação também pode ser deduzido como um de seus possíveis casos, ou seja, corretamente explicado. Ao finalmente substituir a explicação problemática de um fenômeno por uma verdadeira, muda a descrição e, portanto, muda também (como Hilary Putnam mostrou 
usando o exemplo de natural terms [termos naturais]) o significado do fenômeno. Enquanto o sucesso da compreensão hermenêutica de uma expressão é medido pelas condições sob as quais essa expressão pode ser usada em conformidade com a verdade, a lógica da pesquisa visa outra direção: na medida em que esse procedimento de correção da descrição errada conduz à de um fenômeno que necessita de explicação, mudam as condições de verdade para o uso correto de uma expressão, condições estas que são testadas na própria realidade.

Foi decisivo para o desenvolvimento do pensamento de Apel o fato de que Peirce acreditasse um aprimoramento cumulativo da descrição da realidade devido à lógica e à dinâmica do processo de pesquisa. Se os processos de pesquisa, independentemente dos contextos em que se baseiam, se desenvolvem no âmbito de uma comunidade de pesquisa global que aponta para a convergência de uma descrição consistente da realidade como tal, a compreensão prévia estabelecida da realidade a partir da qual parte a próxima geração de pesquisadores também deve mudar. No que diz respeito ao seu ponto de partida, Peirce também é um hermeneuta, uma vez em que ele só pode confiar na fantasia criadora de hipóteses de pesquisadores para abduzir uma nova e verdadeira hipótese na medida em que a experimentação especulativa não se baseia no princípio do acaso, mas em uma "estrutura prévia" intuitivamente conhecida. Ao mesmo tempo, os processos de aprendizagem, totalmente independentes dos diferentes pontos de partida, só podem convergir para o mesmo objetivo de conhecimento da realidade porque têm força para rever a respetiva compreensão prévia. A concepção peirceiana, portanto, rompe com o primado heideggeriano da função de abertura do mundo da précompreensão linguística em relação à verdade dos enunciados que se torna possível por meio dela. ${ }^{8} \mathrm{~A}$ abdução carece do caráter impositivo da dedução e até mesmo da probabilidade de inferência indutiva; apenas nos coloca na trilha de uma visão hipotética que precisa de confirmação empírica. O consenso alcançado no processo de pesquisa tem a última palavra (mesmo que possa ser questionado à luz de novas evidências e em relação a um final consensus [consenso final] que ainda não foi alcançado). À luz desta visão peirceiana, o Apel de 1969 pergunta ao Apel de 1959 com ênfase: "O que impede a hermenêutica de aderir ao princípio regulador da explicação de sentido de Peirce (isto é, o progresso científico - J.H.)" (APEL, 1973f, 208). A hermenêutica deve ser 'transcendental' apenas no sentido de que os avanços no conhecimento resultam da interação poderosa de revisão entre a compreensão de mundo proposta linguisticamente e aqueles processos de aprendizagem intramundanos, que in the long run [a longo prazo], por sua vez, podem revisar a pré-compreensão holística e assim 
podem alterá-la como um todo. Os guardiões da razão universal são, em última análise, os processos de aprendizagem que se baseiam no "princípio regulador de uma verdade absoluta de compreensão em uma comunidade ilimitada de interpretação e interação" (APEL, 1973f, 217 ff.), ou seja, medido pelo caráter incontornável de um consenso universal alcançado fundamentalmente em discursos racionais.

(4) A extensão tácita da comunidade de interpretação dos pesquisadores à comunidade de interação dos sujeitos socializados em sua comunicação cotidiana, presente na última citação, corresponde ao teor daquelas três famosas conferências de 1868 (APEL, 1975), com as quais o jovem Peirce fundou a tradição pragmática:

O processo final e de interpretação do conhecimento transmitido por signos está agora inscrito no processo vital do comportamento controlado pelo sucesso, e o objetivo desse processo não parece mais ser o consenso da verdade na comunidade ilimitada de pesquisadores, mas apenas aquela 'fixação de uma crença' que restitui a segurança do comportamento que é abalada em caso de dúvida, estabelecendo um novo hábito comportamental (habit'), praticamente (experimentalmente) comprovado (APEL, 1973, II, 193).

Mas é só o próprio que Apel irá extrair uma importante implicação dessa transição da pesquisa para a prática cotidiana ao longo do esclarecimento metodológico das diferenças entre explicação causal e compreensão hermenêutica. Em seu mundo cotidiano, os sujeitos não apenas precisam lidar com um ambiente no qual suas ações instrumentais com respeito a fins podem falhar; não se trata apenas da verdade de hipóteses empíricas que, se forem problematizadas e não puderem ser melhoradas ad hoc, devem ser posteriormente processados e esclarecidos na comunidade de interpretação dos pesquisadores. Em seus contextos sociais de interação, os atores também são confrontados com questões normativas no sentido mais amplo - com questões de avaliação controversa de objetos, situações e experiências, com questões éticas de autocompreensão de indivíduos e comunidades, também com a interpretação de experiências estéticas ou religiosas, mas sobretudo com a solução de conflitos de ação morais, jurídicos e políticos prementes. Essas questões normativas em sentido mais amplo não podem ser tematizadas e resolvidas de acordo com o padrão da lógica da pesquisa. É verdade que existem especialistas para cada um deles (assim como especialistas em filosofia, ciências humanas e sociais); mas sua reflexão permanece mais 
intimamente ligada à prática cotidiana e inserida nas "comunidades de interação histórica" do que ocorre com a elaboração teórica de questões científicas - pelo menos quando este se torna independente metodologicamente um processo de pesquisa.

Por outro lado, as mesmas estruturas gerais da linguagem ordinária cotidiana, geralmente presentes na socialização comunicativa, também se refletem na prática comunicativa da comunidade de pesquisa, que visa o progresso do conhecimento. Uma implicação dessa consideração é a mudança do a priori do fundamento incontornável da comunicação linguística. Com a localização do discurso da comunidade de pesquisa na prática comunicativa cotidiana, aquela se desloca para o mundo da vida ainda não foi especificado em termos funcionais. Portanto, Apel (1973g, 389) agora defende "a tese de que o mundo da vida sempre foi interpretado linguisticamente e o a priori do entendimento cotidiano (sic!) no contexto do mundo da vida em um sentido mais preciso é a condição incontornável da possibilidade e validade intersubjetiva de qualquer construção de uma teoria filosófica ou científica concebível e também a... reconstrução da própria linguagem". Com esse deslocamento do a priori para a prática comunicativa do mundo da vida, Apel agora parece concluir que as crenças normativas ainda vêm antes do nível de reflexão da prática de pesquisa funcionalmente especificada. Em todo caso, nesse texto, publicado em 1970, ele traça o rumo que torna possível sua variante original de ética do discurso que inclui a pretensão de "fundamentação última". Vejo o motivo dessa decisão em um certo apego à perspectiva da epistemologia. Para entender isso, gostaria de lembrar brevemente de uma alternativa teoricamente importante que escolhi nessa encruzilhada. Só posso tentar fazer justiça à fascinante honestidade de um grande filósofo, e especialmente de um amigo como Karl-Otto, que subordinou tudo em sua vida à consistência de seus pensamentos, se eu mesmo, que aprendi tanto com ele, esclarecer as razões complexas de nossa divergência - não na substância, mas na fundamentação da ética do discurso. Ao fazer isso, apenas aproveito a oportunidade imerecida daquele que ainda está vivo sabendo que nossa amizade sempre ocorreu na forma de um diálogo em que ambos estavam dispostos para aprender. Ninguém pode ter a última palavra de qualquer maneira. Mas são outros que têm que me contradizer e irão me contradizer no espírito de Karl Otto.

Naquela época, fazia sentido para mim continuar o caminho inovador que Apel havia trilhado da semântica lógica à pragmática formal a partir da semiótica de Peirce, com base na análise de enunciados realizada por Frege, na direção de uma pragmática formal da linguagem. A teoria dos atos de fala desenvolvida por J. L. Austin e John Searle serviu para a elaboração de 
uma pragmática formal que direciona a visão para a comunicação linguística em geral, isto é, à medida que a teoria da linguagem abandona a via kantiana da teoria do conhecimento. Trata-se da dupla estrutura ilocucionária-proposicional dos atos de fala e, acima de tudo, daqueles universais que são performativamente dominados por um falante competente e que - como o sistema de expressões referenciais e especialmente de pronomes pessoais - são constitutivos para o uso de proposições em atos de fala. Essa pragmática formal também leva em conta o fenômeno em que Apel abordou do ponto de vista epistemológico: a distinção entre ação comunicativa e discursos racionais - mas agora dentro de limites que não se restringem à pesquisa científica. As pretensões de validade levantadas para enunciados na realização de atos de fala geralmente só podem ser feitas sob os rigorosos pressupostos pragmáticos de um discurso racional, isto é, na troca regrada, argumentos pró e contra, enquanto tais, são tematizados e testados. Além disso, o método de descobrir o conteúdo idealizado das pressuposições necessárias e universais e, portanto, "incontornáveis", baseia-se na própria estratégia de análise da Apel. Desse ponto de vista da pragmática formal, a comunicação entre os pesquisadores é um caso excepcional, mas especial. Assim como as pretensões de verdade ingenuamente levantadas e aceitas no cotidiano são problematizadas e se tornam objeto do discurso - independentemente de se temporariamente ou na forma metodologicamente consistente de um processo de pesquisa institucionalizado - o mesmo ocorre com as pretensões de validade prática. O exame discursivo da validade de um enunciado tem em todos os casos o mesmo sentido epistêmico de justificação com base em razões. Em contraste, o sentido das pretensões de validade assume diferentes dimensões, dependendo se o enunciado se relaciona com a existência de fatos, com o reconhecimento intersubjetivo de normas morais ou legais, com a "beleza" ou, de modo geral, com o potencial apelativo que a natureza e a arte têm com uma afecção extraordinária de nossos sentidos ou, por fim, com a preferência por valores comuns e intersubjetivamente compartilhados ou hierarquias de valores ordenadas transitivamente. E uma vez que as pretensões de validade para enunciados descritivos, morais, estéticos e (de modo mais restrito) éticos se relacionam a algo no mundo ou - sob os aspectos mencionados - a algo no mundo da vida, que já está simbolicamente estruturado, os respectivos padrões de justificação também variam com o sentido correspondentemente da validade que orientam a troca discursiva de argumentos.

Dependendo da pretensão de validade, no entanto, o tipo de padrão de justificação e o tipo correspondente de razões também variam em seu 
poder de discriminação. Assim, nem as recomendações éticas, nem mesmo os juízos estéticos estão relacionados com pretensões de validade universal. Apenas enunciados morais (e - mutatis mutandis - enunciados legais) reivindicam uma universalidade análoga à verdade, de modo que, especialmente desde a distinção claramente traçada por Hume entre juízos morais e descritivos, uma comparação entre esses dois modelos de raciocínio correspondentes foi apresentada. Para testar questões empíricas e teóricas, Peirce analisou tal padrão de justificação com sua lógica da pesquisa. Consequentemente, uma transformação pragmática do princípio kantiano de universalização é apropriada para a fundamentação de juízos morais: só são válidas as normas que recebessem assentimento de todos os concernidos no discurso prático. Esse procedimento ético-discursivo requer uma operação de universalização justificada de interesses com uma participação fundamentalmente inclusiva de todos os potencialmente concernidos, de forma que somente as máximas se tornem lei, que todos tanto pela consideração mútua, assim como cada um de seu respectivo ponto de vista - por boas razões possam querer. Apel não se opôs a essa conclusão, mas curiosamente, ele próprio se absteve de justificar um princípio moral correspondente. Uma vez que, dadas suas premissas, tal desiderato não se colocou, ele foi capaz de chegar a uma fundamentação dos princípios morais pela via epistemológica, que desde o início impõe uma abordagem transcendental, sem o suposto desvio por uma teoria pragmático-formal da linguagem. Apel chega a respostas morais não apenas refletindo sobre a questão "O que devo fazer?", mas, antes de qualquer distinção entre questões de validade teóricas e práticas, por meio de um aprofundamento da própria reflexão epistemológica: pois "a 'objetividade' da ciência livre de valores (pressupõe) a validade intersubjetiva das normas morais." (APEL, 1973g, 395). Em outras palavras: a razão prática é o cerne da razão teórica, de modo que certas normas morais fundamentais são inerentes às condições pragmáticas de exame discursivo das condições de um conhecimento empírico possível.

Se bem entendi, a ética do discurso pode ser entendida, do ponto de vista de Apel, como o resultado de uma transformação linguística da filosofia transcendental kantiana, pois a hermenêutica transcendental, ao perseguir a questão epistemológica fundamental, encontra não apenas a prática argumentativa dos próprios pesquisadores, mas também certas implicações morais de sua disposição para cooperar e se entender mutuamente, dado que a comunicação dos investigadores se deve a sua inserção nas atividades comunicativas da prática quotidiana. A participação no discurso dos pesquisadores, por sua vez, pressupõe a disposição de compartilhar a responsabilidade pelos sucessos (ou fracassos) a serem 
alcançados coletivamente, sobretudo a veracidade de todos os envolvidos na comunicação e "o reconhecimento mútuo de todos os membros como parceiros iguais" (APEL, 1973g, 400). Apel rebate a objeção de que essas exigências normativas para o propósito especial da empreendimento "pesquisa" são funcionais e, portanto, imperativos meramente hipotéticos, com a tese de "que o mundo da vida é sempre interpretado linguisticamente e o a priori do entendimento linguístico no contexto do mundo da vida em um sentido mais preciso é a condição incontornável da possibilidade e validade intersubjetiva de toda formação de teoria filosófica ou científica concebível e também... a reconstrução da própria linguagem" (APEL, $1973 \mathrm{~g}, 389)$. A comunidade ilimitada de interpretação de pesquisadores está enraizada na "comunidade de interpretação de uma comunidade ilimitada de interação" do mundo da vida, de modo que a reflexão mais uma vez aprofundada no mundo da vida sobre a questão epistemológica só encontra o fundamento absolutamente incontornável de uma troca regrada de razões na prática cotidiana. E esse a priori da comunicação na linguagem ordinária, como pode ser demonstrado pelo envolvimento do cético em contradições performativas, tem por sua vez um conteúdo normativo. Baseado em Husserl, Apel irá mais tarde chamar isso de "discurso primordial". Apel defende a tese fundacionista de que os discursos racionais, nos quais se refletem as pretensões da verdade ingenuamente levantadas na ação comunicativa, já pressupõem um forte ethos de comunicação e - analogamente ao acúmulo de conhecimento - apontam inclusive para o progresso moral:

Se considerarmos que a comunidade real da comunicação, que o argumentador assume na situação finita, de forma alguma corresponde ao ideal da comunidade ilimitada de interpretação, mas está sujeita a todos os limites da consciência e dos interesses da espécie humana dividida em nações, classes, jogos de linguagem e modos de vida, esse contraste entre o ideal e a realidade da comunidade de interpretação também dá origem ao princípio regulador do progresso prático, com o qual o progresso da interpretação poderia e deveria estar entrelaçado (APEL, 1973, II, 215).

Neste caso, também, a antecipação contrafactual de um estado final visa a um consensus omnium - mas não a um acordo dos pesquisadores sobre a totalidade dos fatos, mas a um entendimento dos membros que agem comunicativamente de um mundo social globalmente expandido sobre as normas de sua coexistência. 
(5) Na minha opinião, o programa da ética do discurso é tão pouco afetado pelo poder de persuasão dessa estratégia de fundamentação filosófica transcendental quanto a extensão inovadora que Apel propõe da hermenêutica a uma investigação das propriedades formais dos processos discursivos de comunicação. Como mencionei, considero a passagem crítica da análise lógico-semântica para a análise formal-pragmática da linguagem (e a mudança de paradigma da filosofia da consciência para a filosofia da linguagem) como sua realização inovadora. Mas no momento da transição da razão teórica para a razão prática, mesmo após a mudança de paradigma, Apel se atém à questão epistemológica ${ }^{9}$ : a razão teórica, e esse é o passo que não posso seguir, enraíza-se na reflexão sobre o processo de pesquisa no mundo da vida sobre seus próprios limites. Isso cria uma hierarquia de níveis de autorreflexão do conhecimento, que remete a uma origem comum da razão teórica e da razão prática. Na medida em que amplia as condições da objetividade das experiências possíveis, isto é, a reflexão transcendental de Kant, que limita o uso teórico da razão, parar análise dos pressupostos necessários e universais do uso da linguagem orientado para o entendimento, Apel pretende revelar um ethos inerente à socialização comunicativa como tal. Para fazer isso, ele usa seu procedimento original: o conteúdo ético desses pressupostos pragmáticoformais pode ser demonstrado pelo fato de que qualquer cético que duvide deles se envolve em autocontradições performativas ao entrar em um discurso racional. Dessa forma indireta, Apel justifica, por exemplo, que se deve esperar, de cada participante do discurso, pelo menos a sinceridade e o tratamento igual de todos os outros participantes. O ancoramento primordial na prática comunicativa do mundo da vida pretende dar a esse ethos o estatuto fundacional de "fundamentação última", antes de se desdobrar em discursos sobre questões de natureza teórica ou prática. Em um exame mais detido, no entanto, essa construção falha devido ao estreitamento epistemológico da estratégia de fundamentação e a renúncia explícita a uma destranscententalização da razão, o que, como veremos, teria sido sugerido pelas próprias investigações de Apel, apesar de todas as suas afirmações em contrário.

Se alguém reconstruir de modo imparcial o conteúdo dessas pressuposições pragmáticas universais e necessárias, que todo participante competente em discursos racionais deve assumir de forma indireta, pela via indireta contradições performativas, chegará a uma camada normativa de idealizações fortes, que são adequadas ao propósito epistêmico de testar a validade dos enunciados, mas não a conteúdos éticos. Pois os pressupostos do discurso mencionados a seguir não revelam o sentido do dever moral. ${ }^{10}$ Nas pressuposições, a partir das quais os participantes competentes em 
argumentar devem proceder em suas contribuições, refletem-se as condições epistêmicas de possibilidade para uma troca discursiva de temas, razões e informações, que (a) não excluem da participação ninguém que pudesse dar uma contribuição relevante; que (b) concedem a todos os participantes oportunidades iguais dar uma contribuição; que (c) obrigam os participantes a serem sinceros: eles devem querer dizer o que dizem; e que (d) estão livres de coerções externas e internas (!) de tal forma que as tomadas de posição sim-e-não frente a pretensões de validade criticáveis podem ser determinadas apenas pela coerção não coercitiva do melhor argumento. Nesses pressupostos, sem os quais não se cumprem as condições de comunicação de um discurso racional, reconhecemos, entre outras coisas, as normas de veracidade e igualdade de tratamento enfatizadas por Apel; elas implicam inclusive uma "corresponsabilidade", se por ela se entender apenas a disposição de mobilizar tanto as informações relevantes e melhores possíveis quanto as razões que possam servir para alcançar a verdade, bem como para reconhecer o resultado falível for the time being [por ora]. Mesmo essas restrições específicas são uma reminiscência do propósito exclusivamente epistêmico dos discursos racionais. Enquanto forma de reflexão da ação comunicativa, o discurso racional herda dessa ação a "orientação para o entendimento", na qual o papel coordenador da ação do entendimento por meio da linguagem e a força persuasiva do reconhecimento intersubjetivo de pretensões de validade criticáveis se baseiam na prática comunicativa cotidiana. No entanto, trata-se exclusivamente da força persuasiva epistêmica das melhores razões em cada caso, que motivam racionalmente o acordo sobre o conteúdo de um enunciado, sem que tal entendimento sobre o conteúdo da comunicação resultem em razões impositivas para uma ação conjunta fora do discurso.

Isso é evidente no caso das pretensões de verdade examinadas em discursos teóricos ou empíricos; pois aqui as "obrigações" de veracidade e igualdade de tratamento resultantes dos pressupostos do discurso referemse apenas à própria prática do discurso; para que percam seu sentido, elas devem ser seguidas no interior próprio discurso. É óbvio que uma violação desses pressupostos do discurso é disfuncional, mas não pode ser contestada no sentido moral; porque não intervém em contextos de ação per se e não afeta diretamente interesses que poderiam ser violados em um sentido normativo. A orientação para o entendimento, que está ligada ao exame discursivo de uma pretensão de verdade, tem por si mesma um sentido puramente epistêmico. Isso é medido pelo fato de a razão decisiva falar a favor ou contra a existência dos fatos afirmados. Algo muito similar acontece com uma pretensão de validade moral controversa relativa a um 
tipo geral de comportamento ou (sob determinadas circunstâncias e à luz de normas moralmente reconhecidas) para um determinado comportamento. A correção de uma norma moral controversa depende de se as razões sugerem que é do interesse igual de todos os que possíveis concernidos (e a adequação de um comportamento moralmente questionável depende de corresponder, em circunstâncias dadas, a uma norma moralmente reconhecida). Os discursos práticos, por tratarem de normas de ação que afetam os sujeitos da ação em suas diversas situações de vida, também exigem que os participantes do discurso estejam dispostos a assumir perspectivas recíprocas. Mas mesmo nesses casos trata-se do sentido exclusivamente epistêmico da questão moral-cognitiva de se um tipo de comportamento ou um comportamento deve ser reconhecido como moralmente obrigatório certo ou errado. No entanto, há uma diferença sutil, mas significativa, entre os discursos teóricos e práticos. Como a forma semântica de um enunciado descritivo já aponta para o sentido da pretensão da verdade, a existência de fatos, a pretensão de validade assertórica que é levantada para enunciados desse tipo não parece ter que ser introduzida no discurso de fora; as pretensões de verdade só têm sentido relativamente à estrutura lógica dos enunciados para os quais foram levantadas; eles constituem uma parte, por assim dizer, imanente do discurso, mesmo que a explicação mais detalhada do significado da pretensão da verdade deva se referir a algo "existente" ou "subsistente" no mundo objetivo. Ao contrário, o significado da pretensão de validade normativa que é levantada para enunciados morais só pode ser explicado com referência a pretensões de validade que já existem ou ainda serão realizadas fora do discurso; pois tal pretensão de validade, antes que possa ser tematizada como tal na troca discursiva de enunciados, se vincula a uma norma que só existe ou pode continuar a existir no modo de validade normativa reconhecida. As normas morais só podem existir se sua validade for reconhecida pelos sujeitos comunicativamente socializados e, a partir desse reconhecimento intersubjetivo, possam contar de fato com o cumprimento. Em contraste com a pretensão de verdade levantada para enunciados, a pretensão de validade tornada problemática de uma norma moral ou uma ação correspondente só pode ser tematizada no discurso depois de ter sido importada do mundo da vida para o discurso.

Por isso, o modo de validade normativa dos enunciados morais não pode ser derivado do conteúdo idealizado de qualquer pressuposto do discurso, mas apenas do sentido obrigatório e do poder socialmente integrador das normas sociais que exigem consideração dos sujeitos de ação. ${ }^{11} \mathrm{~A}$ pretensão de validade de correção moral tratado no discurso não retira seu sentido do próprio discurso, mas da pretensão de 
reconhecimento, com a qual aparecem os princípios e normas morais existentes ou a serem realizados em uma sociedade. Se, no entanto, ao contrário da suposição de Apel, nenhum ethos moralmente obrigatório pode ser derivado da orientação para o entendimento que os sujeitos que agem comunicativamente devem pressupor quando entram em um discurso racional, os participantes devem introduzir o conceito de validade normativa, por meio do qual eles podem se valer de sua tem experiência de vida social em discursos de fundamentação e de aplicação. $E$, ao invés de uma justificação transcendental, que a ética desenvolve diretamente a partir do "a priori" da comunidade de comunicação do mundo da vida, uma justificação ética do discurso de enunciados morais, como mencionado, requer um procedimento análogo à justificação de enunciados teóricosempíricos. ${ }^{12}$

(6) Não preciso voltar aqui à minha própria tentativa, publicada pela primeira vez em 1983, de fundamentar o princípio da universalização com base na fórmula legislativa do imperativo categórico. ${ }^{13}$ Esta estratégia de fundamentação faz uso do método de Apel de reconstruir o conteúdo dos pressupostos pragmáticos universais e necessários dos discursos racionais, sem, é claro, pretender extrair dessas próprios pressupostos o sentido obrigatório do modo de validade normativa, por meio do qual as normas morais obrigatórias se tornam efetivas no mundo da vida. Uma obrigação moral não pode resultar apenas, por assim dizer, da necessidade transcendental de pressupostos inevitáveis da argumentação; ela depende, antes, das normas que se tornaram problemáticas introduzidas nos discursos prático-morais, às quais se referem as razões pró e contra. Mas se os pressupostos da argumentação não podem suportar o fardo de uma fundamentação transcendental da qualidade de dever moral dos mandamentos, o estatuto incontornável da argumentação que Apel explora não pode mais reivindicar o sentido forte de um a priori transcendental. 0 modo discursivo de examinar as pretensões de validade criticáveis que levantamos para enunciados é "incontornável" apenas no sentido factual mais fraco de que essa prática de dar e receber razões (Brandom) para sujeitos comunicativamente socializados não tem um equivalente funcional em nenhuma uma das formas de vida socioculturais que conhecemos. Acho que essa concepção destranscendentalizada da "incontornabilidade" resulta igualmente da própria base antropológica da epistemologia de Apel. Talvez seja esse problema não resolvido no pano de fundo de sua teoria que levou um pensador consequente como Apel a mais tarde adicionar uma "Parte B" à sua ética de discurso que dá uma resposta à pergunta: Por que devemos ser morais? ${ }^{14}$ Para ser respondida teleologicamente, essa pergunta não pode ser feita, muito menos respondida, dentro do arcabouço da ética 
deontológica. Esse problema exigiu que Apel introduzisse uma supernorma que, paradoxalmente, nos impõe ser morais. Não posso tratar disso aqui. Mas, para concluir, vale a pena especular sobre a razão da tenacidade com que Apel se apegou à fundamentação transcendental última da ética do discurso. Suspeito que a razão esteja na relação problemática de uma pretensão de fundamentação transcendental da razão prática com a história e a evolução social de sujeitos socializados que existem no espaço e no tempo.

Quando a questão kantiana sobre o que devemos fazer perde seu pano de fundo transcendental e depende do fato de que existem normas obrigatórias cuja pretensão de validade normativa podemos examinar criticamente de um ponto de vista moral, surge a questão preocupante de saber se ainda existem hoje normas categoricamente obrigatórias - e se devem existir. Podem as normas, que em determinadas circunstâncias ordenam absolutamente um determinado comportamento a seus destinatários, ou seja, sem consideração das consequências, ainda reivindicar "existência" nas sociedades seculares da modernidade ocidental a tal ponto que, no caso de sua problematização, se tornem objeto de crítica e exijam fundamentação? Certamente, como cientistas sociais, podemos constatar da perspectiva de um observador que mesmo nas áreas de atividade amplamente secularizadas das sociedades modernas, sobretudo nos padrões de socialização nos sistemas de educação formal e nas formas de interação informal de quase todas as áreas da vida, nos sistemas jurídicos e nos Estados constitucionais, estão incorporadas ideias de justiça que muitas vezes ainda têm um núcleo deontológico de obrigações incondicionais. Um exemplo famoso é a decisão do Tribunal Constitucional Federal de 15 de fevereiro de 2006 segundo a qual o conteúdo do §14, Parágrafo 3 da Lei de Segurança Aérea, que deixa a critério das autoridades do Estado pesar as vidas de um grande número de pessoas ameaçadas contra as vidas de um número limitado de outras, ordenando que um avião seja abatido para proteger vidas no solo, viola a dignidade humana (Art. 1. Lei Fundamental) e o direito fundamental à vida (Art. 2.0, Parágrafo 2 da Lei Fundamental). A própria incerteza sobre se tais decisões, que eram justificadas deontologicamente naquele momento, continuarão a existir no futuro, é uma evidência de que a filosofia não pode mais se apoiar nessa "autoevidência" como pôde Kant (que ainda partia do sentimento de dever como um fato transcendental). Pois, desde o século XVII, não apenas as tentativas filosóficas de reconstruir esse núcleo da ética religiosa na forma do direito racional e da moral racional têm prevalecido, mas também abordagens concorrentes de tipo não-cognitivista, que descartam a estrita autocompreensão moral de pessoas responsáveis como uma ilusão de modo 
empírico ou naturalista. Deste ponto de vista, o dever categórico, que se combina com as ideias deontológicas de justiça, é uma intuição baseada no autoengano. É difícil imaginar que crianças, que crescem em famílias ou ambientes sociais equivalentes sem o dever categórico de imperativos obrigatórios, não se tornem monstros clínicos. Mas é difícil estimar até que ponto essas interpretações "esclarecidas" contribuirão no curso de uma maior modernização capitalista para minar as crenças deontológicas de justiça e substituir estas por um número crescente de sistemas de ação através de cálculos racionais ou teóricos de benefícios (passando por sistemas de saúde já em prática).

Essas sugestões destinam-se apenas a chamar a atenção para o burden of argument [ônus do argumento], que de um ponto de vista filosófico estritamente transcendental não deveria existir. Se, no entanto, de um ponto de vista pós-metafísico, as normas morais, como componentes históricos de nossas formas socioculturais de vida, podem ter sido geradas, em última análise, apenas pelos próprios sujeitos comunicativa e socialmente associados no curso da evolução social, é compreensível que no curso da secularização da moral a questão: "O que devo fazer?" se transformou na questão reflexiva: "Por que devo ser moral?". Uma vez que essa questão não pode ser descartada de imediato, nem pode ser respondida dentro do arcabouço de uma ética deontológica, tentei tornar compreensível no quadro ampliado de uma história da filosofia as razões pelas quais o pensamento pós-metafísico, na constelação formada por Hume e Kant, se dividiu em tradições opostas e de que maneira - após a destranscendentalização da razão - uma fundamentação discursiva da moral racional ainda pode ser defendida com melhores razões contra o derrotismo. De certo modo, o próprio Kant já dá uma resposta dialética: uma vez que ele estabelece o princípio moral com o auxílio de um conceito de autonomia, que vincula o livre arbítrio do indivíduo justamente àquelas leis que todos os possíveis concernidos podem querer por boas razões, cada um pode responder à pergunta: "Por que ser moral, afinal?" dizendo que somente a resposta afirmativa permite que eles se vejam como sujeitos "que agem autonomamente". É verdade que moralidade e liberdade se referem uma à outra no próprio conceito de autonomia; mas se nós, como Kant, estamos principalmente preocupados com a autocompreensão do ser humano como um ser racional autônomo, há uma boa razão - no sentido deontológico - para ser "moral" mesmo sem certezas transcendentais: porque só assim podemos nos entender como autônomos. ${ }^{15}$ 


\section{Notas}

1 Traduzido do original alemão por Antonio Ianni Segatto (UNESP). Revisado por Denilson Luís Werle (UFSC).

Uma versão deste artigo foi publicada em: "Von der formalen Semantik zur transzendentalen Pragmatik - Karl Otto Apels ursprüngliche Einsicht", Topologik, 26, 2019, 66-88.

${ }^{2}$ No prefácio a Karl-Otto Apel (1973, I, 7), o autor comenta o título, fazendo uma autoironia, com as seguintes palavras: "O leitor certamente notará, ao folhear o sumário de ambos os volumes, que a posição do próprio autor sofreu uma transformação".

3 "Esta integração do mundo linguístico é agora - com todas as raízes transcendentais no logos em geral e com toda a validade universal prática para a comunidade linguística associada - vista do ponto de vista excêntrico da reflexão filosófica sobre a verdade, mas deve ser caracterizada sempre como dogmática, no sentido de uma relação cêntrica com o ser-no-mundo histórico corporal... de uma comunidade linguística" (APEL, 1973a, 132).

${ }^{4}$ Reimpresso em Habermas (1981).

5 "A constituição mundial, que se diferencia nos tipos de estrutura linguística, cria e assegura ao ser humano por milhares de anos um análogo do 'ambiente' animal (no sentido de Uexkülls), até então na área do tipo de língua indo-européia, que a 'diferença ontológica' expressa na forma interna da linguagem de modo particularmente claro (mais precisamente: 'pensa à frente'), o problema filosófico estabelece uma compreensão do ser que precede toda percepção dos entes (as ideias categorias, entes enquanto tais)" (APEL, 1973a, 62).

${ }^{6}$ Esse também foi o tom de minha resenha a "Urmensch und Kultur", em Habermas (1956).

7 Por exemplo, em Habermas (1968). Nesta ocasião, devo mencionar a penetrante crítica de Apel, da qual tirei uma lição importante. Isso foi dirigido contra minha confusão da "autorreflexão" no sentido de emancipação de uma ilusão particular, isto é, baseada biograficamente ou historicamente com a "autorreflexão" no sentido da reconstrução racional de competências universais. Isso imediatamente fez sentido para mim (ver o epílogo de "Conhecimento e interesse" (1973)) e foi de grande importância para meu trabalho posterior.

${ }^{8}$ Cf. Apel (1973, I, 43): "Uma vez que que a 'abertura do ser-aí' descoberta por Heidegger, que precede todas as operações cognitivas subjetivas, não é em si mesma verdade, mas pressupõe verdade e inverdade possíveis no sentido de uma margem, não há razão para seguir Heidegger em sua 'virada' e separar o problema da constituição do problema da justificação.".

${ }^{9}$ Isso pode ter se imposto tanto mais fortemente para Apel dado que ele já havia lidado com Ser e tempo de uma perspectiva epistemológica em sua dissertação de Bonn. Na introdução à sua tese de habilitação sobre a "ideia de linguagem", ele se inspirou em Gadamer e Peirce, ou seja, dois autores, que também desenvolveram seus conceitos de linguagem e interpretação do ponto de vista metodológico de uma hermenêutica ou de uma lógica da pesquisa. 
10 Estou desconsiderando o fato de que os discursos racionais não se limitam ao exame das pretensões da verdade e das pretensões morais de correção, mas também se relacionam às pretensões de validade de enunciados jurídicos, éticos e estéticos.

${ }^{11} \mathrm{O}$ mesmo vale para todas as pretensões de validade normativas que podem se tornar objeto do discurso. Porque um estatuto ontológico social, bem como as normas morais, reivindica valores éticos habituais incorporados em formas de vida e normas jurídicas socialmente válidas; as pretensões de validade que levantamos para enunciados estéticos derivam de uma promessa incorporada na própria obra de arte, de conter um potencial de experiência extraordinária para um observador ou ouvinte sensível. No caso da beleza natural, tal pretensão é levantada pelo sujeito sensível ao vivenciar uma paisagem natural. Assim como as outras pretensões de validade normativa, o sentido da validade de tal juízo também não pode ser extraído do conteúdo dos pressupostos universais e necessários do discurso.

${ }^{12}$ Agradeço a Smail Rapic por chamar minha atenção para o fato de que da escolha temática do meu foco na "ruptura" de Apel em direção à transformação da filosofia transcendental sugere uma imagem incompleta. Nas últimas "disputas" (APEL, 1998, em particular p. 649-839), Apel não modificou sua posição inicial em vista de uma fundamentação última, mas - em busca de fato princípio metodológico frutífero de "autorrecuperação" - modificou o apriorismo kantiano em favor de uma relação dialética entre razão e história. A tese de que Apel acabou se referindo à figura hegeliana do pensamento da reflexão absoluta (especialmente em Apel (2014)), tendo visado uma nova arquitetura teórica, relativizaria a importância que a estratégia inicial de fundamentação tem no contexto do conjunto da obra de Apel. Cf. RAPIC (2019) especialmente cap. VIII.

13 Habermas (1983) cf. também o breve resumo sistemático do argumento em Habermas (1996).

14 Não vou me deter nisso porque vai além do período de desenvolvimento da teoria do discurso de Apel até 1973.

15 Mesmo que, depois da destranscendentalização da razão, não possamos mais considerar o senso de dever como uma espécie de fato inato ou transcendental e, em vez disso, tenhamos que considerar o fato de que cada vez mais "o sentimento de dever só surge do dever categórico da razão prática legislativa, é verdade que isso pode motivar o arbítrio apenas pela força das boas razões a vincular-se às leis racionais. Mas o dever é agora (segundo a interpretação proposta, segundo a qual gostaríamos de nos compreender como autônomos no curso dos processos históricos de aprendizagem) sustentado pela autocompreensão de um ser racional autônomo, que se articula em uma extensa teia de razões. Assim, com a 'crença na razão', Kant queria encontrar um equivalente razoavelmente justificado para aqueles que estavam cansados de exigências morais excessivas e tinham esperança de felicidade oferecida pela fé na justiça de Deus. Além disso, para que razão não se desespere com o derrotismo pairando em si, ele construiu pontes na filosofia da história... É um conjunto complexo de razões entrelaçadas que deveriam encorajar a autocompreensão necessária" (HABERMAS, 2019, II, 805). Em vez das razões que hoje não nos convencem mais, tentei interpretar os 
processos de aprendizagem encorajadores da história da filosofia. Indo além das razões, que em última análise apenas sugerem tal interpretação, também desenvolvi razões sistemáticas no pós-escrito para esta história que podem sustentar a frágil confiança na própria força. Resumindo em uma frase: "A autocompreensão do ser humano como ser racional autônomo pode buscar coragem sobretudo nos traços históricos daqueles processos de aprendizagem moral-prática que se corporificam no aumento das liberdades institucionalizadas e sobretudo hoje nas práticas e garantias jurídicas de estados constitucionais democráticos" (HABERMAS, 2019, II, 806). 


\section{Referências bibliográficas}

APEL, Karl-Otto. Die Idee der Sprache in der Tradition des Humanismus von Dante bis Vico. Bonn: Bouvier: 1963, p. 17-94.

APEL, Karl-Otto. Transformation der Philosophie. Band I/II. Frankfurt am Main: Suhrkamp, 1973.

APEL, Karl-Otto. "Der philosophische Wahrheitsbegriff als Voraussetzung einer inhaltlich orientierten Sprachwissenschaft (1959)". In: APEL, KarlOtto. Transformation der Philosophie. Band I/II. Frankfurt am Main: Suhrkamp, 1973a, v.I, p. 106-137.

APEL, Karl-Otto. "Arnold Gehlens Philosophie der Institutionen und die Metainstitution der Sprache". In: APEL, Karl-Otto, Transformation der Philosophie. Band I. Frankfurt am Main: Suhrkamp, 1973b.

APEL, Karl-Otto. "Szientistik, Hermeneutik, Ideologiekritik (1966, 1968)". In: APEL, Karl-Otto. Transformation der Philosophie. Band II. Frankfurt am Main: Suhrkamp, 1973c., p. 96-127.

APEL, Karl-Otto. "Karl-Otto Apel, Von Kant zu Peirce (1970)". In: APEL, Karl-Otto. Transformation der Philosophie. Band II. Frankfurt am Main: Suhrkamp, 1973d.

APEL, Karl-Otto. "Die Kommunikationsgemeinschaft als transzendentale Voraussetzung der Sozialwissenschaften". in: APEL, Karl-Otto. Transformation der Philosophie. Band II. Frankfurt am Main: Suhrkamp, 1973e.

APEL, Karl-Otto. "Szientismus oder transzendentale Hermeneutik (1959)". in: APEL, Karl-Otto. Transformation der Philosophie. Frankfurt am Main: Suhrkamp, $1973 f$.

APEL, Karl-Otto. "Das Apriori der Kommunikationsgemeinschaft und die Grundlagen der Ethik". In: APEL, Karl-Otto. Transformation der Philosophie. Band II. Frankfurt am Main: Suhrkamp, 1973g.

APEL, Karl-Otto. Der Denkweg von Charles S. Peirce (1967), Frankfurt am Main: Surhkamp, 1975, p. 73-105.

APEL, Karl-Otto. Auseinandersetzungen in Erprobung des transzendentalpragmatischen Ansatzes. Frankfurt am Main: Suhrkamp, 1998.

APEL, Karl-Otto. "Transzendentalpragmatik - Drittes Paradigma der Ersten Philosophie". In: RAPIC, Smail (ed.), Habermas und der Historische Materialismus. Freiburg: Karl Alber, 2014, p.87-103. 
HABERMAS, Jürgen. "Zerfall der Institutionen", Frankfurter Allgemeine Zeitung, 7 de abril de 1956.

HABERMAS, Jürgen, Philosophisch-politische Profile, Frankfurt-am-Main, $1981,65-72$.

HABERMAS, Jürgen. "Diskursethik - Notizen zu einem Begründungsprogramm". In: HABERMAS, Jürgen. Moralbewusstsein und kommunikativen Handelns. Frankfurt am Main: Suhrkamp, 1983, p. 93108.

HABERMAS, Jürgen. "Eine genealogische Betrachtung zum kognitiven Gehalt der Moral." In: HABERMAS, Jürgen. Die Einbeziehung des Anderen. Frankfurt am Main: Suhrkamp, 1996, p. 56-64.

HABERMAS, Jürgen. "Rationalität der Verständigung: Sprechakttheoretische Erläuterungen zum Begriff der kommunikativen Rationalität". In: HABERMAS, Jürgen. Wahrheit und Rechtsfertigung, Frankfurt, 1999, p. 102-137.

HABERMAS, Jürgen. Auch Eine Geschichte der Philosophie, Bd. 2, Frankfurt am Main: Suhrkamp, 2019.

RAPIC, Smail. Normativität und Geschichte, Zur Auseinandersetzung zwischen Apel und Habermas, Freiburg: Karl Alber, 2019. 